\title{
Ipsilateral femoral neck and shaft fracture in children: a report of two cases and a literature review
}

\author{
Kwang Soon Song • Kirti Ramnani • \\ Chul Hyun Cho $\cdot$ Ki Cheor Bae $\cdot$ Kyung Jae Lee $\cdot$ \\ Eun Seok Son
}

Received: 21 December 2010/ Accepted: 13 March 2012/Published online: 5 May 2012

(C) The Author(s) 2012. This article is published with open access at Springerlink.com

\begin{abstract}
Concomitant ipsilateral fractures of the neck and shaft of the femur in children are rare. The most recent report in this context found a total of only nine reported cases $(<12$ years of age) following a search of the indexed English literature. These injuries occur in children due to high-velocity trauma, and there is no generally accepted method of treatment. We report three additional cases from the literature and two cases of our own. In our cases, one had a residual $10^{\circ}$ varus deformity at the subtrochanteric level in the femur, but this did not affect hip function. Another patient exhibited a limp at final follow-up due to leg length discrepancy, and peroneal nerve palsy at the time of injury. We advocate operative stabilization of the femoral shaft fracture first to reduce the risk of further displacement and simplify the subsequent reduction of the femoral neck. The series shows that these rare injuries have a poor prognosis, with high rates of incidence of avascular necrosis, coxa vara, and leg length discrepancy.
\end{abstract}

Keywords Femoral neck fracture - Ipsilateral femoral shaft fracture $\cdot$ Children

\section{Introduction}

Concomitant ipsilateral fractures of the neck and shaft of the femur in children are rare. The authors of the most recent report in this context found that only nine cases $(<12$ years of age $)$ have been reported to date, including

K. S. Song $(\varangle) \cdot$ K. Ramnani $\cdot$ C. H. Cho .

K. C. Bae $\cdot$ K. J. Lee $\cdot$ E. S. Son

Department of Orthopedic Surgery, Keimyung University,

194 Dondsandong, Joong-gu, Daegu 700-712, Korea

e-mail: skspos@dsmc.or.kr two of their own cases; the other seven cases were found by searching the indexed English literature [1]. Only one or two cases are reported in each of the works they found in the literature [1-7]. These injuries occur in children due to high-velocity trauma, and there is no universally accepted method of treatment [8]. We report two additional cases with such a combination of injuries as well as three additional reports [9-11] found in the literature. Our study showed that there is a relatively high complication rate with transepihyseal or transcervical femoral neck fractures, so we disagree with the opinion that a symbiotic effect during the time of injury results in a lower incidence of complications [1]. The present study was performed after obtaining informed consent from the patients' parents or guardians.

\section{Case reports}

\section{Case 1}

An eight-year old girl was run over by a car and was subsequently admitted to the hospital with an obvious deformity and swelling in the left thigh. Radiograph revealed a cervicotrochanteric fracture (type III in Delbet's classification [12]; AO classification type II [13]) with a subtrochanteric fracture of the left femur (Figs. 1, 2). Surgery was performed $10 \mathrm{~h}$ after the trauma, after obtaining medical clearance for anesthesia. The treatment included open reduction and plate fixation of the subtrochanteric fracture, and closed reduction and internal fixation of the femoral neck with a screw and Steinmann pins. The proximal fragment of the subtrochanteric fracture was held firmly with bone-holding forceps to prevent further displacement of the femoral neck fracture during reduction 


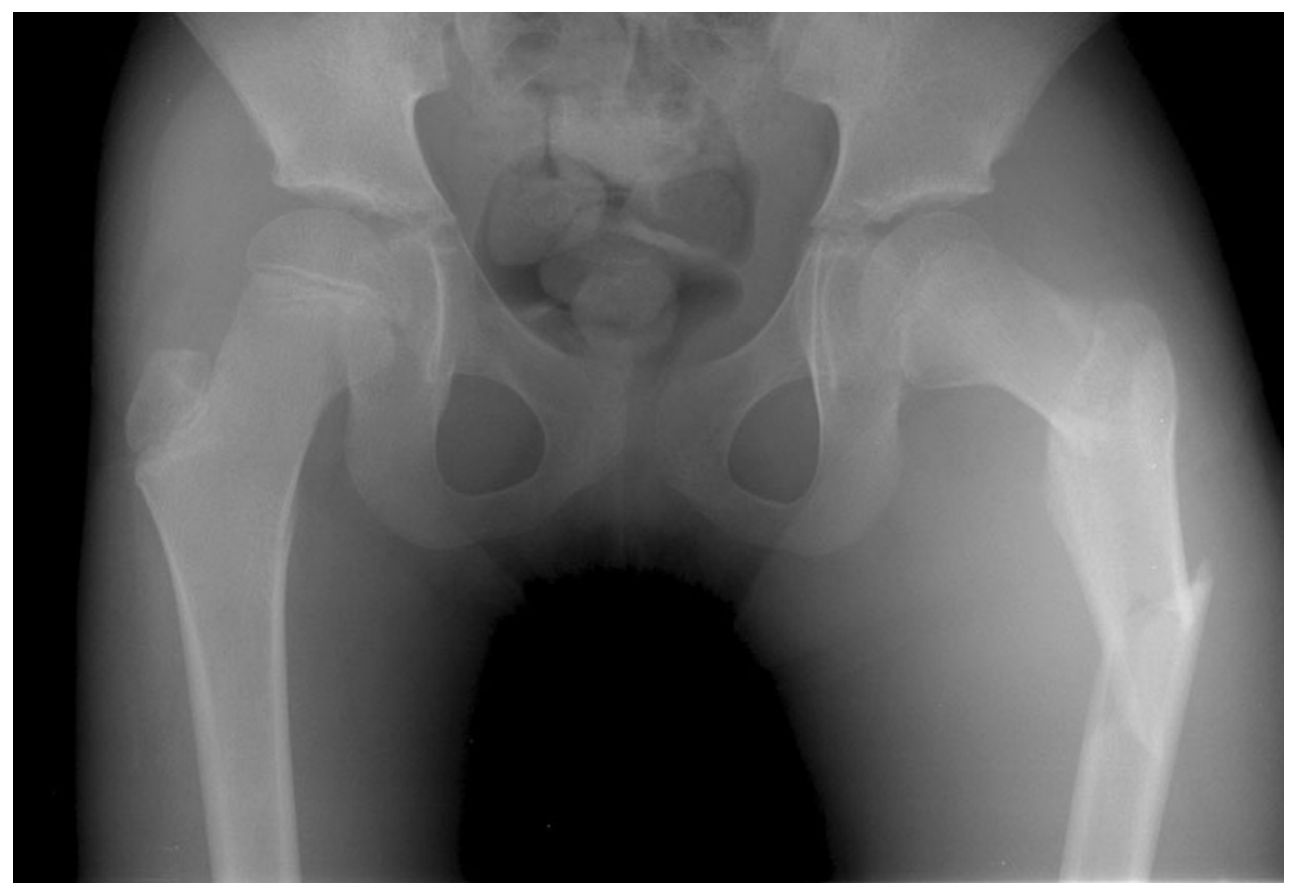

Fig. 1 Eight-year-old girl: anteroposterior radiographs reveal a cervicotrochanteric fracture (type III in Delbet's classification; AO classification type II) with a subtrochanteric fracture of the left femur

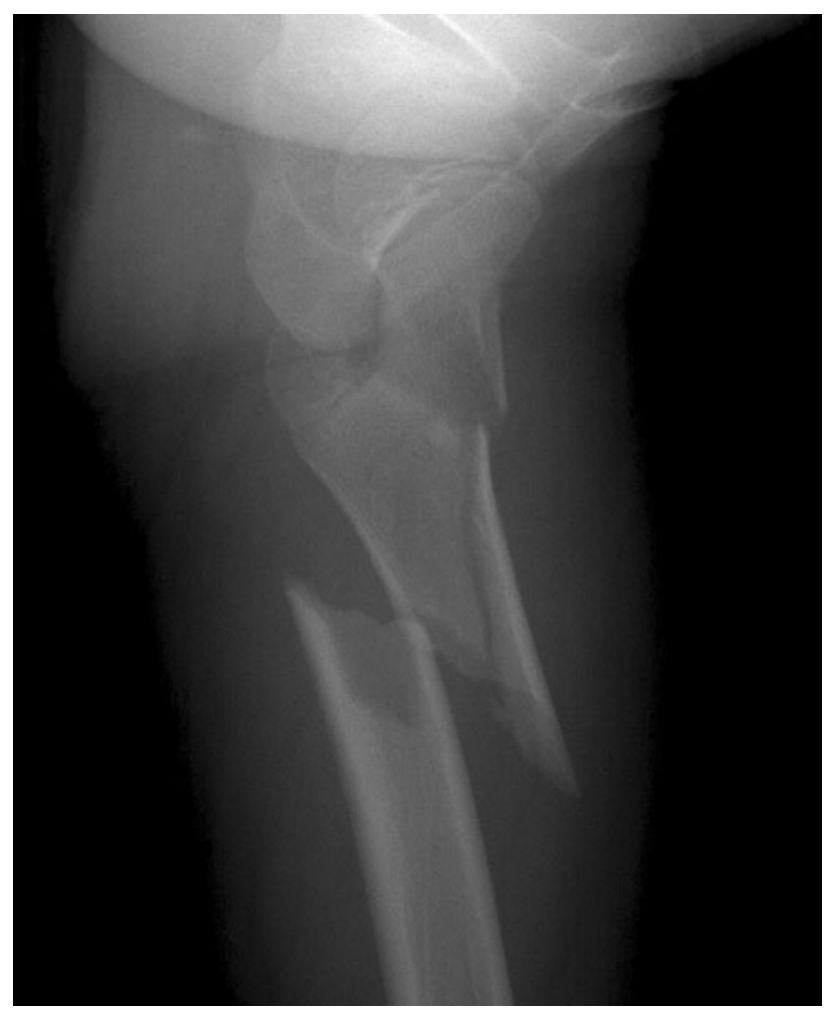

Fig. 2 Eight-year-old girl: lateral radiographs reveal a cervicotrochanteric fracture (type III in Delbet's classification; AO classification type II) with a subtrochanteric fracture of the left femur and application of the plate. Although the subtrochanteric fracture was fixed with a five-hole compression plate, the proximal fragment was fixed with a single screw to avoid impingement during fixation of the femoral neck fracture. The bone-holding forceps were retained until closed reduction and fixation of the femoral neck fracture had been achieved with a single cannulated screw $3.5 \mathrm{~mm}$ in diameter and three Steinmann pins $2 \mathrm{~mm}$ in diameter (Fig. 3). Postoperatively, the child was immobilized in a one-and-a-half hip spica cast (hip flexion $30^{\circ}$ and abduction $40^{\circ}$ for both hips, and knee flexion $30^{\circ}$ for the affected limb) to augment the stability of the subtrochanteric fracture fixation. However, after removal of the cast at two months postoperatively, the radiograph showed a $10^{\circ}$ varus deformity of the subtrochanteric fracture with proximal screw back-out (Fig. 4). We started non-weightbearing mobilization exercises at two months and three weeks postoperatively. Walking exercises were started with an ischial weight-bearing long leg brace four months postoperatively, progressing to full weight bearing by five months. Implant removal was performed 11 months postoperatively. Follow-up at five years after the injury showed normal and painless hip function clinically; radiographs showed no evidence of avascular necrosis of the femoral head or growth disturbance, except for the residual $10^{\circ}$ varus deformity at the subtrochanteric level in the femur (Fig. 5). 


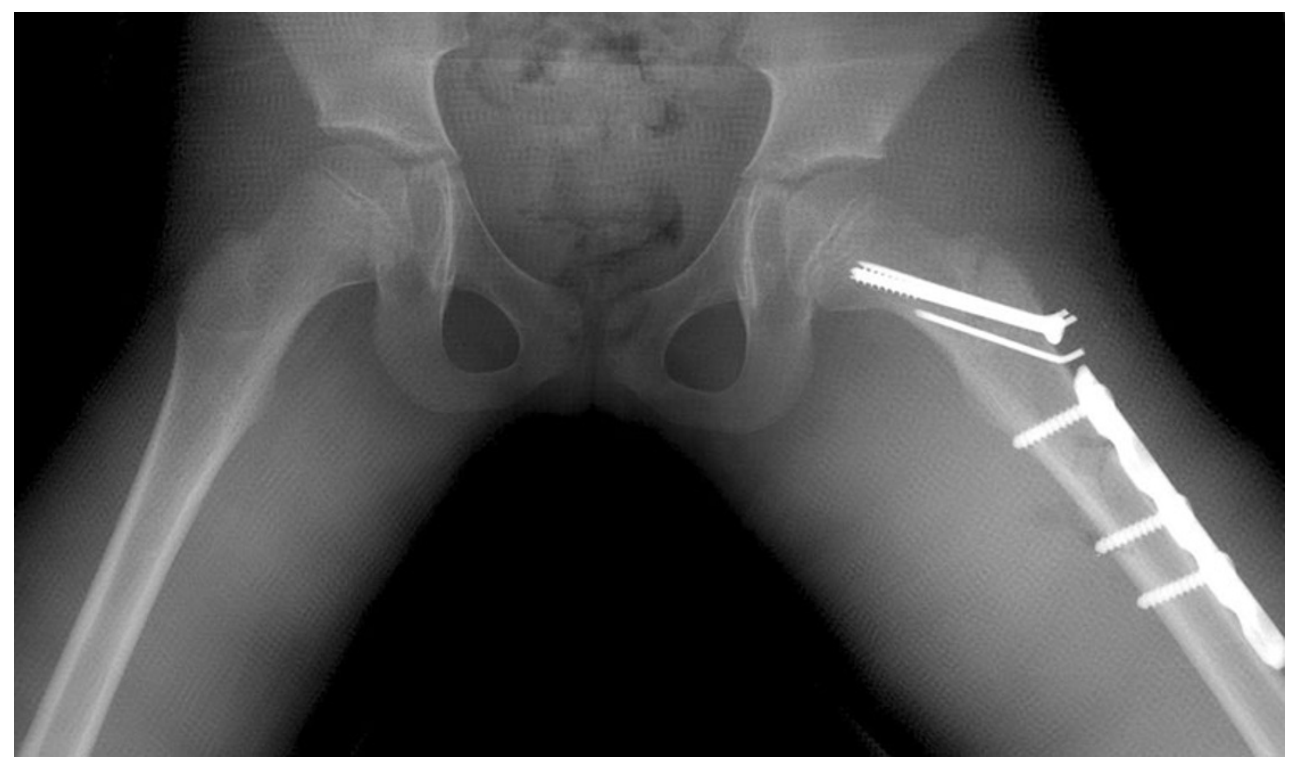

Fig. 3 The neck femur fracture was fixed with a single cannulated screw $3.5 \mathrm{~mm}$ in diameter and three Steinmann pins $2 \mathrm{~mm}$ in diameter, the subtrochanteric fracture was fixed with a five-hole compression plate, and the proximal fragment was fixed with a single screw to avoid impingement during fixation of the femoral neck fracture

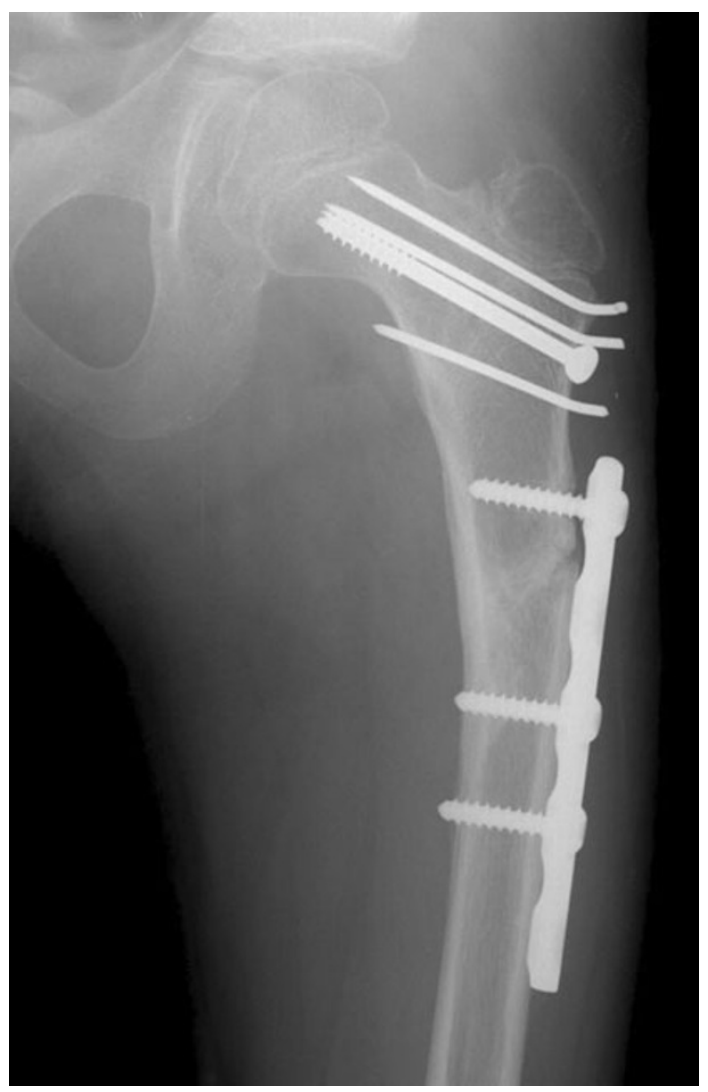

Fig. 4 After removing the cast at two months postoperatively, the radiograph showed a $10^{\circ}$ varus deformity of the subtrochanteric fracture with proximal screw back-out

\section{Case 2}

A boy seven years and ten months of age was involved in a head-on collision with car and admitted to the hospital in a drowsy state. Radiographs revealed a right intertochanteric fracture (type IV in Delbet's classification; AO classification type III) and an ipsilateral lower one-third fracture of the femoral shaft (Fig. 6). He had additional injuries, including subdural brain hemorrhage, lateral condylar fracture of the right humerus, and left distal radius fracture. Immediate skeletal traction was applied to the ipsilateral tibia to prevent further displacement of the fracture and damage to the blood supply of the femoral head. Once the general condition of the patient had improved after 3 days, open reduction and internal fixation of the distal femur fracture with a six-hole dynamic compression plate and closed reduction and internal fixation of the femoral neck fracture with two cannulated screws $3.5 \mathrm{~mm}$ in diameter were performed. The proximal fragment was stabilized with bone-holding forceps during fixation of the femoral shaft fracture to avoid the inadvertent transmission of force to the neck fracture. Postoperatively, the patient was immobilized in a one-and-a-half hip spica cast (hip flexion $30^{\circ}$ and abduction $30^{\circ}$ for both hips, and knee flexion of $30^{\circ}$ in the affected knee). We removed the hip spica cast and started non-weight-bearing active mobilization exercises at six weeks postoperatively (Fig. 7). Walking exercises were started with an ischial weight-bearing long leg brace three months postoperatively, progressing to full weight bearing by four months. Implant removal was done 1 year postoperatively. At the two-year follow-up, 


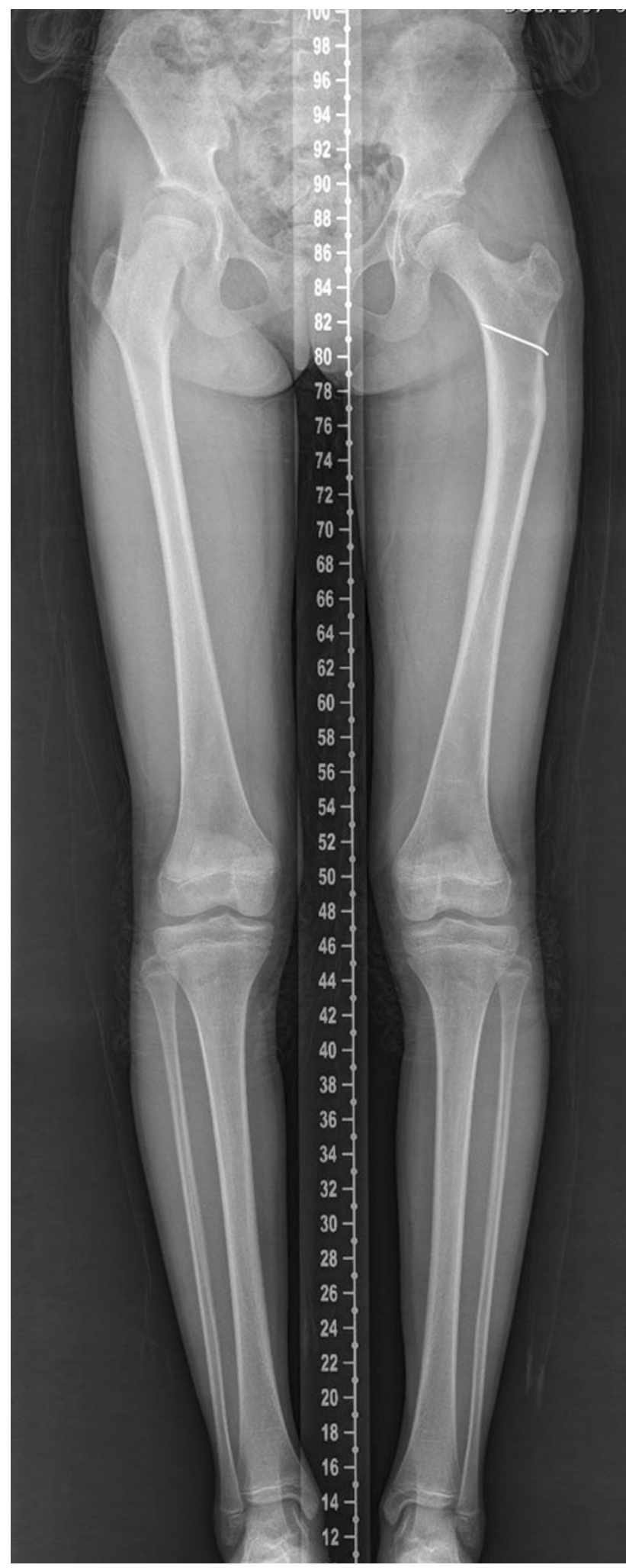

Fig. 5 Telereontgenogram shows no evidence of avascular necrosis of the femoral head or growth disturbance except for the residual $10^{\circ}$ varus deformity at the subtrochanteric level in the femur

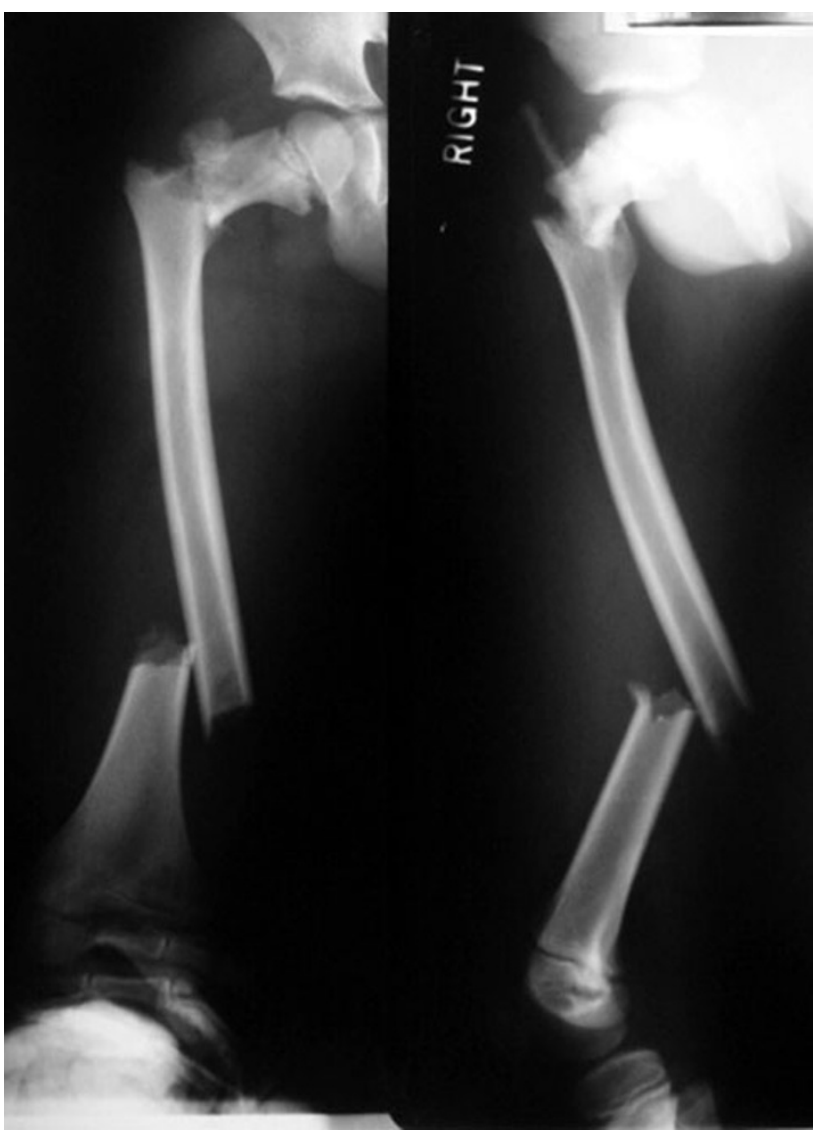

Fig. 6 Boy seven years and ten months of age: anteroposterior and lateral radiographs reveal a right intertochanteric fracture (type IV in Delbet's classification; AO classification type III) and an ipsilateral lower one-third fracture of the femoral shaft

radiographs revealed that there was no avascular necrosis, but an overgrowth of $1.5 \mathrm{~cm}$ was noted (Figs. 8, 9). The patient walked with a limping gait as a sequela of the subdural brain hemorrhage, leg length discrepancy, and unrecovered peroneal nerve palsy.

\section{Discussion}

Displaced femoral neck fractures are uncommon injuries in children [14-23], while concomitant fracture of the neck and shaft of the femur is an even more unusual injury [17]. Bennet et al. [7] reported only one case of ipsilateral hip and femoral shaft fracture in children, as compared to 41 such injuries in adults. In 2008, Agarwal et al. [1] stressed the rarity of this concomitant injury, which can be gauged from searching the indexed English literature. They found only seven cases of such injuries in children less than 12 years of age in the literature. They reported a total of nine cases of such injuries, which included two cases of their own. In this work, we have documented three 


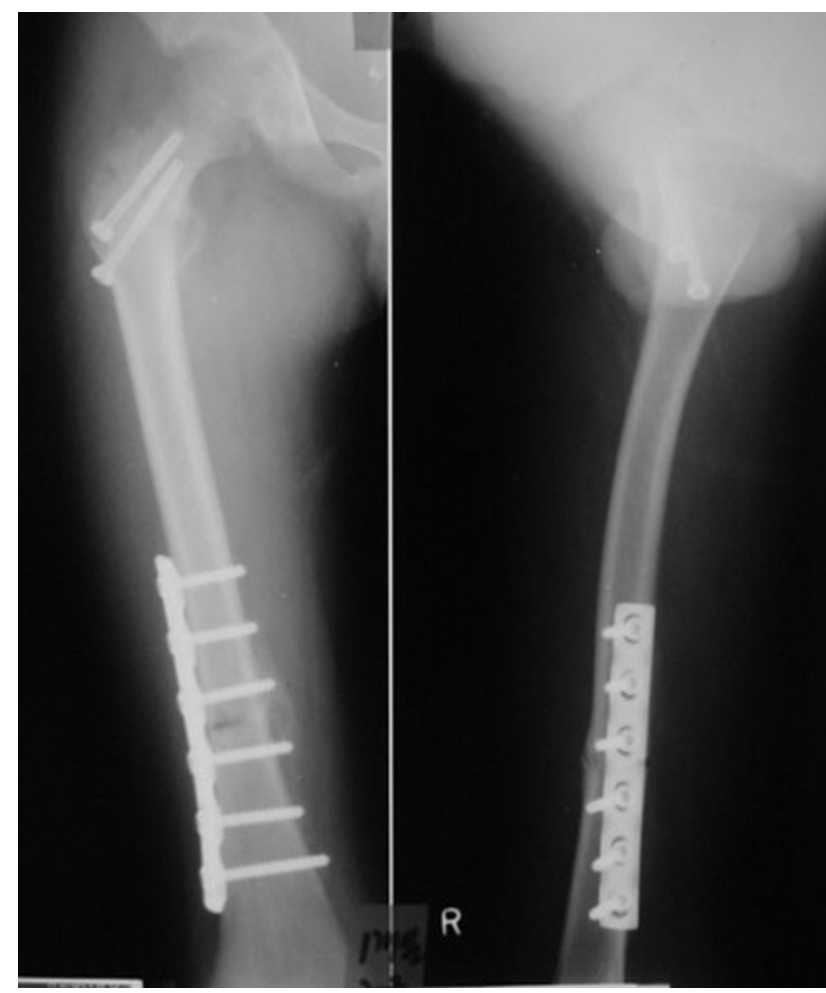

Fig. 7 At six weeks after the operation, the radiographs show wellmaintained reduction. The patient was started on non-weight-bearing active exercises

additional reports that we found in the literature but were missed by Agarwal et al. [1]; two were published in the English literature in 1983 and 2006, respectively [9, 10], while the other was published in German in 1986 [11]. These three reports were published before the report of Agarwal et al. (see Table 1).

Femoral neck fractures in children are well known for their sinister nature and potential for complications, especially avascular necrosis, which poses the most serious problem and has been reported to have a variable incidence $[15,16,18-22]$. It depends on several factors, such as the degree of initial displacement [15, 17-19, 21, 23], the type of fracture [15, 24, 25], and the timing of surgery [16, 24].

Upon reviewing all nine cases documented by Agarwal et al. [1], six of the femoral neck fractures they reported were cervicotrochanteric (Delbet type III; AO type II), one was transepiphyseal (Delbet type I; AO epiphyseal type 1), another was intertrochanteric (Delbet type IV Delbet; AO type III), while the fracture type was insufficiently described to be able to establish it for the other case. The level of concomitant femoral shaft fracture was midshaft in six cases, distal third in one, and the description was insufficient to determine the level in two cases [1-7].

In this study, we have reported an additional five cases (two from our experience and three more reports fould in the literature). The type of fracture neck femur was transepiphyseal (Delbet type I; AO epiphyseal type I) in two cases, cervicotrochanteric (Delbet type III; AO type II) in two cases, and intertrochanteric (Delbet type IV; AO type III) in one case. If all fourteen cases are considered together, the most common type of femoral neck fracture, when associated with ipsilateral femoral shaft injury, is Delbet type III (AO type II) fracture (eight cases).

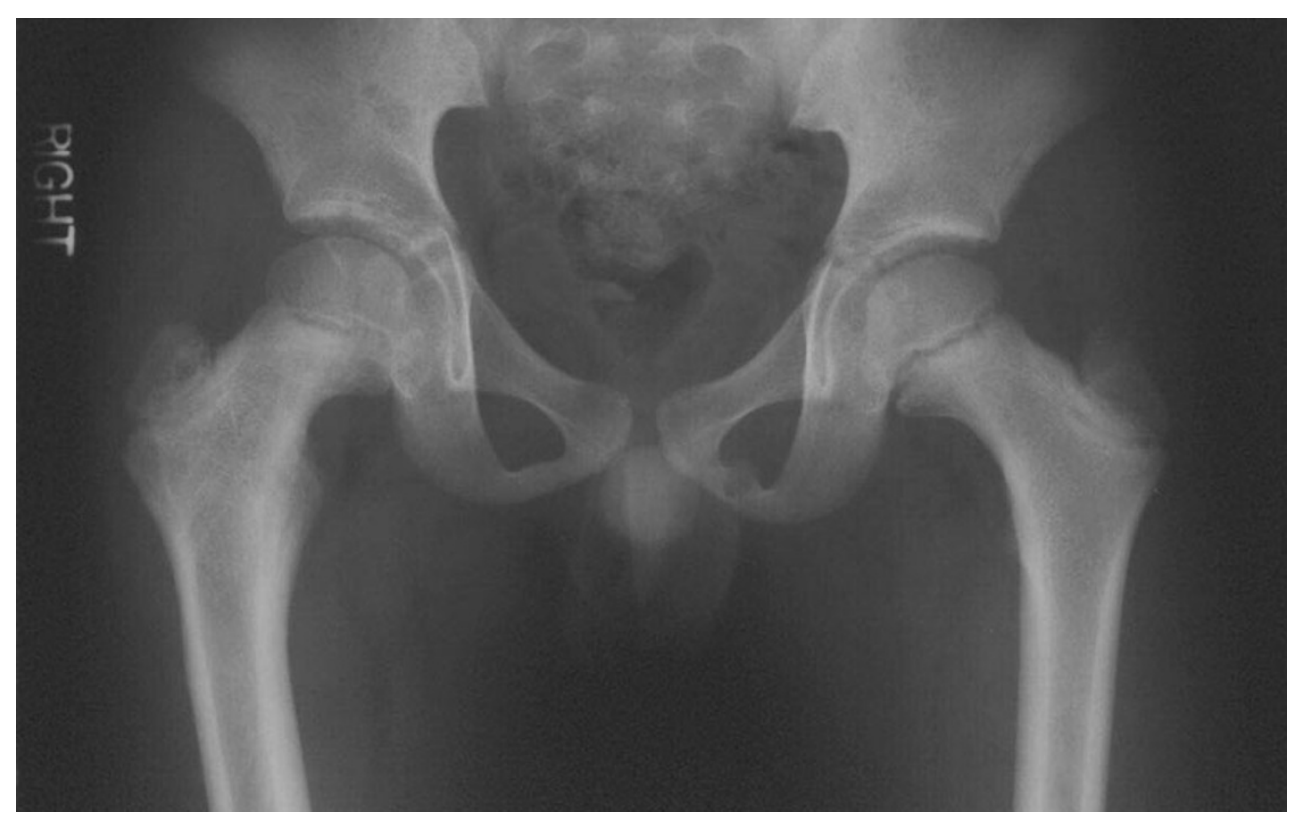

Fig. 8 At two-year follow up, radiographs show union of the femoral neck fracture without avascular necrosis of the femoral head 


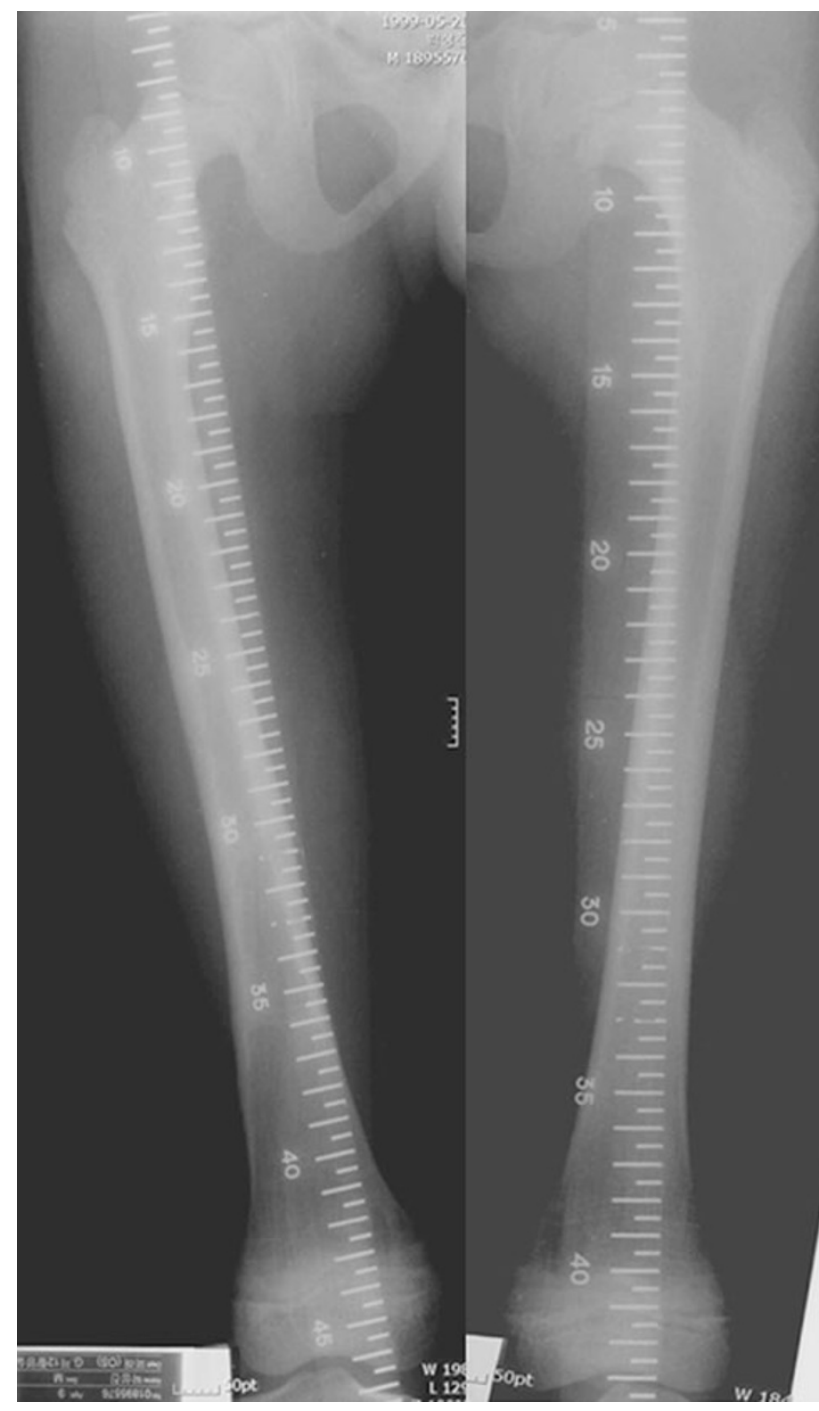

Fig. 9 At two-year follow up, radiographs show overgrowth of the right femur of $1.5 \mathrm{~cm}$

Although it is not easy to define the mechanism of trauma, we believe that the mechanism of injury must be high-energy impact at both fracture sites simultaneously. We do not think that sequential application of high-energy forces after a time interval can produce another fracture on top of an already unstable previous fracture.

Various treatment modalities have been tried for these injuries-operative, conservative, or a combination of both. Although good results have been reported with all of these treatment modalities in the literature [1-7], the authors advocate operative stabilization of these injuries to reduce the risk of further displacement of the fracture and allow early mobilization $[1,11]$. However, we believe that open reduction and internal fixation of the femoral shaft fracture is the only treatment that permits control over and avoids worsening of the ipsilateral femoral neck fracture; we do not favor it solely because it permits early mobilization. We applied a hip spica cast in both of our cases to promote stability at the fracture site.

We recommend prior fixation of the femoral shaft fracture in these injuries, without attempting to reduce the femoral neck fracture initially, as it provides for more easy subsequent manipulation, reduction, and fixation of the ipsilateral femoral neck fracture. In both of our cases, we fixed the femoral shaft fracture with a plate and screw, and followed this with closed reduction and internal fixation of the femoral neck fracture. However, in one case (case 1), reduction of the subtrochanteric fracture was lost due to proximal screw back-out resulting from inadequate fixation of the proximal fragment, which in turn led to a $10^{\circ}$ varus deformity of the proximal femur. In this case, we should have considered the distance between the two fractures to be a prognostic factor, and the possibility of using a lowprofile plate that can be modeled in the proximal part to allow introduction of a screw through the proximal hole of the plate into the femoral neck if the two fractures are too close together. We do not need absolutely stable osteosynthesis, because in children younger than ten years it is always advisable to create a spica cast.

At the 2-year follow-up, there was a residual $10^{\circ}$ varus deformity of the proximal femur without leg length discrepancy, although leg length discrepancy was noted as being a problem in case 2 ; this could have occurred after plate and screw fixation when treating the femoral shaft fracture in the child.

Agarwal et al. [1] also noted that a combination of ipsilateral femoral neck and shaft fracture in children had a low incidence of complications. They proposed that the fractures that occur at the two sites in the same limb probably have a symbiotic effect, and that the impact energy was distributed at the time of the initial trauma, thus preventing extreme damage to either of the fracture sites. However, in their report, they only noted cervicotrochanteric and intertrochanteric types of femoral neck fracture, which are less prone to avascular necrosis than the transepiphyseal or transcervical types. In our review of an additional five cases, two had avascular necrosis of the capital epiphysis: one was a transepiphyseal fracture with major displacement (Delbet type Ib) [9] which was treated with open reduction and internal fixation, while the other was a cervicotrochanteric fracture [11] diagnosed on day 9 and operated on day 23 after the initial injury. We do not agree with the view that a symbiotic effect at the time of initial trauma plays a significant role in the prognosis of these injuries, because our study showed relatively high complication rates with transepiphyseal and transcervical femoral neck fractures, which were not presented in the previous literature.

We believe that prior fixation of the femoral shaft fracture in these injuries simplifies the subsequent 


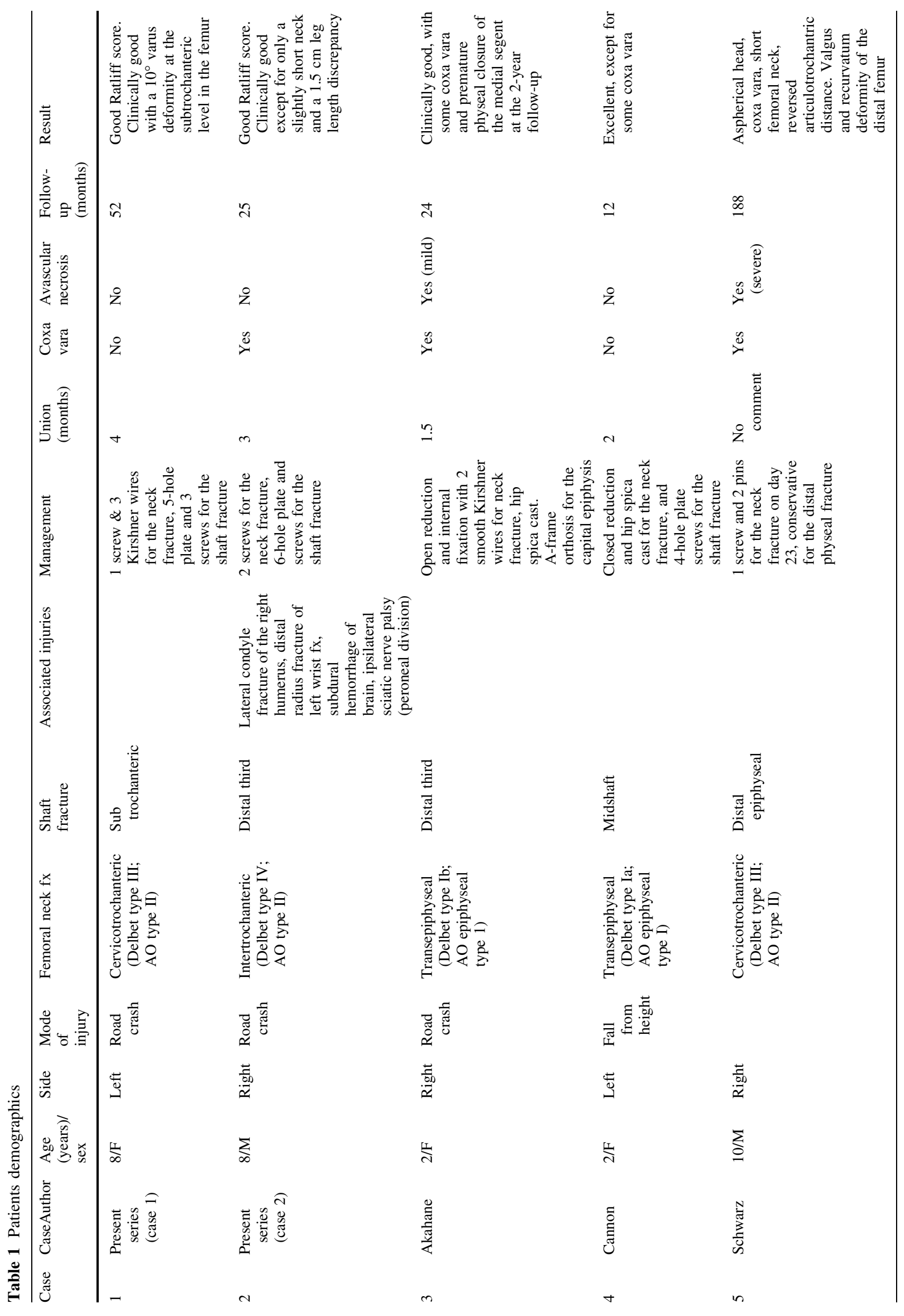


manipulation, reduction, and fixation of the ipsilateral femoral neck fracture, and that the results of these injuries depend on the severity of the initial trauma, the fracture type, and the timing of surgery.

\section{Conflict of interest None.}

Ethical standards I obtained informed consent from the patient's parent and parent approved the publication of this case report.

Open Access This article is distributed under the terms of the Creative Commons Attribution License which permits any use, distribution, and reproduction in any medium, provided the original author(s) and the source are credited.

\section{References}

1. Agarwal A, Agarwal R, Meena DS (2008) Ipsilateral femoral neck and shaft fracture in children. J Trauma 64(4):E47-E53

2. McDougall A (1967) Fracture of the neck of femur in childhood. J Bone Jt Surg Am 49:16-29

3. Fardon DF (1970) Fracture of neck and shaft of the same femur. Report of a case in a child. J Bone Jt Surg Am 52:797-799

4. Hoeksema HD, Olsen C, Rudy R (1975) Fracture of femoral neck and shaft and repeated neck fracutre in a child. Case report. J Bone Jt Surg Am 57:271-272

5. Swiontkowski MF, Hansen ST, Kellam J (1984) Ipsilateral fracture of the femoral neck and shaft. J Bone Jt Surg Am 66:260-268

6. Canale ST (2000) Hip fractures in children. Curr Orthop 14:108113

7. Bennett FS, Zinar DM, Kilgus DJ (1993) Ipsilateral hip and femoral shaft fracture. Clin Orthop Related Res 296:168-177

8. Hoekstra HJ, Binnendijk B (1982) Fracture of the neck and shaft of same femur in children. A report of two cases. Arch Orthop Trauma Surg 100(3):197-198

9. Akahane T, Fujioka F, Shiozawa R (2006) A transepiphyseal fracture of the proximal femur combined with a fracture of the mid-shaft of ipsilateral femur in a child: a case report and literature review. Arch Orthop Trauma Surg 126(5):330-334
10. Cannon SR, Pool CJF (1983) Trauamtic separation of proximal femoral epiphysis and fracture of the mid-shaft of the ipsilateral femur in a child: a case report and review of the literature. Injury $15: 156$

11. Schwarz N, MoosmÜller W (1986) Simultaneous fracture of the femur shaft and femur neck in the children and adolescents. Unfallchirurg 89(6):268-271

12. Colonna PC (1929) Fracture of the neck of the femur in children. Am J Surg 6:793-797

13. Marsh JL, Slongo TF, Agel J, Broderick JS, Creevey W, DeCoster TA, Prokuski L, Sirkin MS, Ziran B, Henley B, Audigé L (2007) Fracture and dislocation classification compendium2007: Orthopaedic Trauma Association Classification, Database and Outcomes Committee. J Orthop Trauma 21 (Suppl 10):S1-S163

14. Ratliff AH (1962) Fractures of the neck of the femur in children. J Bone Jt Surg Br 44:528-542

15. Morrissy RT (1980) Hip fractures in children. Clin Orthop Relat Res 152:202-210

16. Flynn JM, Wong KL, Yeh GL, Meyer JS, Davison RS (2002) Displaced fractures of the hip in children. Management by early operation and immobilisation in a hip spica cast. J Bone Jt Surg Br 84:108-112

17. Canale ST (1990) Fractures of the hip in children and adolescents. Orthop Clin North Am 21:341-352

18. Forlin E, Guille JT, Kumar SJ, Rhee KJ (1992) Complications associated with fracture of the neck of the femur in children. J Pediatr Orthop 12:503-509

19. Heiser JM, Oppenheim WL (1980) Fractures of the hip in children: a review of forty cases. Clin Orthop Relat Res 149:177-184

20. Leung PC, Lam SF (1986) Long-term follow-up of children with femoral neck fractures. J Bone Jt Surg Br 68:537-540

21. Hughes LO, Beatty JH (1994) Current concepts review: fracture of the head and neck of the femur in children. J Bone Jt Surg Am 76:283-292

22. Swiontkowski MF, Winquist RA (1986) Displaced hip fractures in children and adolescents. J Trauma 26:384-388

23. Morsy HA (2001) Complications of fractures of the neck of the femur in children. A long-term follow-up study. Injury 32:45-51

24. Moon ES, Mehlman CT (2006) Risk factors for avascular necrosis after femoral neck fractures in children: 25 Cincinnati cases and meta-analysis of 360 cases. J Orthop Trauma 20:323-329

25. Togrul B, Bayram H, Gulsen M, Kalaci A, Ozbarlas S (2005) Fractures of the femoral neck in children: long-term follow-up in 62 hip fractures. Injury 36:123-130 